0361-3682(94)E0017-0

\title{
THE ROLE OF PROFESSIONAL CONTROL IN THE MANAGEMENT OF COMPLEX ORGANIZATIONS*
}

\author{
MARGARET A. ABERNETHY \\ The University of Melbourne \\ and \\ JOHANNES U. STOELWINDER \\ Monash Medical Centre
}

\begin{abstract}
The limitations of formal administrative controls in organizations performing complex production tasks have created the need for less obtrusive forms of management control. When formal administrative controls cannot cater to the unpredictability of complex work demands, one strategy is to employ "professionals" who have been trained to cope with these demands and whose behaviour is primarily controlled through social and self-control mechanisms. There is some question, however, as to the effectiveness of this strategy. There is evidence that integrating professionals into bureaucratic organizations creates the potential for a "clash of cultures". Conflict emerges when salaried professionals engage in behaviour directed towards increasing their own autonomy (or in some cases maintaining it) and management implement control systems designed to control that behaviour. This paper argues that the degree of conflict experienced will depend on the individual role orientation of the professional and the extent to which management confront professionals with bureaucratic administrative systems which restrict their self-regulatory activities. The study was undertaken in a large public teaching hospital in Australia and the results support the theoretical position taken in the paper.
\end{abstract}

Accountants concerned with the management of complex organizations need a "wider vision" of control and an understanding of the interplay between the administrative controls they often design and implement, and the informal control processes which operate within organizations (Hopwood, 1976). Nowhere is this more important than in human service organizations where core production activities are dominated by professionals. ${ }^{1}$ Professionals are employed in

\footnotetext{
- The authors gratefully acknowledge the financial support provided by the Faculty of Economics and Commerce at the University of Melbourne and the Monash Medical Centre. Our appreciation is extended to Peter Brownell, Jere Francis, Nonman Macintosh, Kennelh Merchant and Nick Dopuch for their insiglitul comments on this paper and to participants at the European Accounting Conference (Madrid), AAANZ Conference (Palmerston North, N.Z.), and to numerous colleagues who attended the Accounting \& Finance Workshop at The University of Melbourne. The constructive criticisms of anonymous reviewers and Anthony Hopwood were also much appreciated.

' There has been considerable debate in the sociology literature as to the traits of a professional and the social and political factors which influence the development of a profession (see Abbott, 1988; Davies, 1983; Barley \& Tolbert, 1991). Leading sociologists studying professionals recognize the futility of finding any widely accepted definition of the term professional and argue that it is important for "writers on the topic ... to display to readers what they have in mind when the word is used ..." (Freidson, 1983, p. 35). Following others, the term "professional" is used in this study to refer to a group of workers (e.g. nurses, doctors, lawyers, academics, etc.) who, by virtue of their knowledge and expertise, are employed to perform complex production tasks and thus are treated differently (or expect to be treated differently) from other workers as well as from management (Barley \& Tolbert, 1991; Derber \& Schwartz, 1991).
} 
these settings to accomplish complex tasks for which formal administrative controls are poorly suited (Zucker, 1991). These individuals have been trained to perform complex tasks independently and to solve problems which arise in the performance of these tasks using their experience and expertise (Derber \& Schwartz, 1991). They are socialized according to a model of control which emphasizes social and self-controls. There is, however, the potential for a "clash of cultures" when professionals are incorporated into bureaucratic organizations (Raelin, 1989). When core production processes become dependent on the expertise of professionals, these individuals often gain considerable autonomy within the organization. This autonomy becomes problematic when professionals demand, and often achieve, control not only over the process of the work but also over the purposes or ends of the work (Barley \& Tolbert, 1991; Derber \& Schwartz, 1991). Organizations are reluctant to grant professionals these special rights as they are likely to conflict with management goals and bureaucratic principles of management.

Accounting systems are implicated in the relationship between professionals and organizations as these systems are designed and implemented to achieve bureaucratic criteria of efficiency and accountability. They are often implemented with little concern for the unique aspects of the delivery of professional services. An illustration of this is taking place in the hospital sector where cost containment efforts are increasing the pressure for the implementation of new and sophisticated management control systems (Preston et al., 1992). An implicit objective of these policy initiatives is to increase control over the behaviour of the professionals who have traditionally dominated decision making in hospitals (Chua \& Degeling, 1991 ). While this dominance is seen as adverse to the efficient and effective delivery of health care services, increased levels of bureaucratic control may not be the panacea. Hospitals run the risk of becoming trapped in what Crozier
(1964, p. 187) refers to as a "bureaucratic vicious circle". As these organizations attempt to impose administrative controls on professionals, this provokes a new effort on the part of professionals to evade these controls, which is then countered by a new round of standardizing regulations, and so on until the organization "becomes frozen into a completely inflexible structure" (Young \& Saltman, 1985, p. 36). Not only does this behaviour threaten organizational survival, it also has adverse effects on the professionals associated with these organizations (Copur, 1990).

There is very little research in the accounting literature studying control systems in professionally dominated organizations despite the rapid shift of professionals from self-employed to salaried employment. ${ }^{2}$ The few studies which do exist have tended to be based on socioeconomic and political frameworks (Broadbent et al., 1991; Chua \& Degeling, 1993; Preston et al., 1992). This paper adopts a much more functionalist perspective and examines the implications when formal administrative controls, such as accounting controls, are implemented in organizations dominated by professionals. We are particularly interested in the conditions which influence the extent to which this form of control will lead to adverse consequences. The paper reports on a study undertaken in one large teaching hospital in Melbourne, Australia, using a sample of nurse and physician managers. The focus on the hospital sector reduces the risk of overgeneralization (see Ginsberg, 1988) and yet enables a study of control in what is considered to be a highly complex industry (Perrow, 1986; Shortell et al, 1990). The study is particularly relevant to managers in this sector as significant resources are currently being devoted to the development of management accounting systems and there is some question as to the efficacy of these systems (Abernethy \& Stoelwinder, 1991; Pollitt et al., 1988; Packwood et al., 1991; Preston et al., 1992).

The paper is organized as follows. The

\footnotetext{
${ }^{2}$ Nearly three-quarters of all professionals are now employed in organizations (Copur, 1990).
} 
following section develops the conceptual framework resulting in testable hypotheses. Subsequent sections describe the method, present the results and discuss the implications of the findings.

\section{CONCEPTUAL FRAMEWORK}

\section{Prior literature}

In much of the early research the concept of organization control was perceived as an administrative process "designed to regulate the activities of organization participants and, by implication, output" (Mills, 1983, p. 445). As a consequence, much of our understanding of management control systems has come from investigating mechanisms which are implemented by senior management to control work through observing and monitoring behaviour and the outputs which result from that behaviour (Merchant, 1985; Birnberg \& Snodgrass, 1988). These control mechanisms have often been termed administrative or bureaucratic controls and include such mechanisms and procedures as authority structures, rules, policies, standard operating procedures, budgets, reward and incentive systems (Hopwood, 1976; Hellriegel \& Slocum, 1986). Numerous models of control have been developed and tested in both the organization behaviour and accounting literatures which indicate that as production processes become increasingly complex and unpredictable, traditional administrative controls have been found wanting (Hirst, 1983; Merchant, 1985). It is in this situation where organizations often resort to what Orlikowsky (1991, p. 11) refers to as "professional control".

Professional control is similar to Ouchi's (1979) notion of clan control in that it is based on social and self-control processes. It occurs when the organization hires personnel who are equipped with coping mechanisms which enable them to apply their expertise in conditions of uncertainty (Perrow, 1986). These individuals are seen to have not only the necessary knowledge and experience to per- form complex tasks, but they have also been socialized to act independently without formal administrative controls, and can search for and implement desired solutions. It is expected that professional behaviour will be controlled through self-control processes and the social controls imposed by individuals within the professional group (Orlikowsky, 1991). Most of the control literature has argued that these less formal controls are desirable when bureaucratic forms of control cannot cater to the unpredictability of complex work demands and tended to ignore the potential for dysfunctional behaviour (Merchant, 1985; Ouchi, 1979). It is assumed that social and self-controls are functional because they are supplemented by training and socialization strategies implemented by management to instil and reinforce congruence between the goals and values of individuals and those espoused by the organization. These strategies are designed to facilitate the acceptance of bureaucratic norms and values. This, in turn, enables the organization to trust individuals to behave in a way which is consistent with the achievement of organizational objectives (Ouchi, 1979).

Professional control, however, is an external form of control as it has "its roots outside the organization" and stems from the social control imposed by individuals within the professional group (Orlikowsky, 1991, p. 11). Internal socialization policies, therefore, will not necessarily be effective in ensuring that organizational values and norms are internalized. This is particularly evident in organizations such as hospitals and universities where the profession often remains the dominant socialization agent (Derber \& Schwartz, 1991; Lurie, 1981). There is no option in these organizations but to rely on professional modes of control as professionals have traditionally controlled core production processes (Mintzberg, 1979). In addition, hospitals and universities are generally structured on a not-for-profit basis and hence their charters preclude provision of incentives to reinforce organizational values. There is, therefore, some concern as to the effectiveness of professional control. This concern has taken two directions. 
One has been to question the notion that professionals can be trusted to serve the public good. Johnson (1977) and Freidson (1970, 1975 ) both exemplify this more sceptical view of professionals and demonstrate how different groups of professionals have exploited their expertise in organizations to achieve the necessary dominance and authority to pursue activities which satisfy their own goals and objectives rather than those of the organization.

A second line of inquiry stems from the literature which has focused on the conflict experienced by professionals when they become salaried employees and confront the values and norms which underlie bureaucratic organizations (Hall, 1967; Scott, 1966; Raelin, 1989; Copur, 1990). The literature, based on this sociological paradigm, views the model of control which underlies professional behaviour as antithetical to the control model that underlies bureaucratic organizations (Scott, 1966). Considerable research has been devoted to studying the sociological problems which arise when professionals are integrated into bureaucratic organizations. ${ }^{3}$ This research almost invariably assumes that sole practice is the proper form of employment for professionals and that inserting professionals into bureaucratic organizations will inevitably result in conflict (Barley \& Tolbert, 1991; Davies, 1983). Copur (1990, p. 114) summarizes the differences in the two institutional forms of organizing work which are seen to give rise to professional/bureaucratic conflict:

Bureaucratic tasks are partial and training is short and within the organization, while professional jobs are complete and training takes long years outside the organization. Bureaucrats are loyal to the organization and legitimate their acts by invoking organizational rules while professionalism requires loyalty to the profession and legitimizing of action based on technical competence. In bureaucracies, compliance is supervised by hierarchical superiors. As a contrast, professional compliance is elicited through socialization and internalization of ethical norms set by a community of peers.

The assumption that the relationship between professionals and bureaucratic organizations is necessarily conflictual has been challenged (Davies, 1983; Barley \& Tolbert, 1991). Barley and Tolbert (1991), however, argue that the notion of professional/bureaucratic conflict should not be discarded but rather that it be viewed as an empirical question instead of an ideology - that is, conflict be seen as one of degree rather than as an absolute. What is becoming of interest to researchers studying behaviour in professionally dominated organizations is a specification of the conditions which give rise to conflict and the structural and other control arrangements required for accommodating professional demands for autonomy and management's desire to impose formal administrative controls to achieve bureaucratic criteria of efficiency and accountability (Derber \& Schwartz, 1991; Sitkin \& Sutcliffe, 1991; Tolbert \& Stern, 1991 ). This study follows this line of inquiry. In particular, the study is concerned with assessing the extent of conflict experienced when management control systems are implemented into professionally dominated organizations and the factors which influence the degree of conflict (if any) experienced by professionals. The hypothesis to be tested is developed as follows.

\section{Designing management control systems in professional bureaucracies 4}

Role theory tells us that individuals experience conflict when there is "... the simultaneous occurrence of two (or more) sets of pressures such that compliance with one would make difficult or impossible compliance with the other" (Wolfe \& Snoke, 1962, p. 103). The potential for role conflict to emerge when professionals become integrated into bureaucratic organizations will depend on the extent

\footnotetext{
${ }^{3}$ See Abbott ( 1988 ) for a review of this literature.

${ }^{4}$ Mintzberg (1979) used the term "professional bureaucracy" to refer to organizations, such as hospitals and universities, which rely on the skills and knowledge of their professionals to perform core operating activities.
} 
to which there are fundamental differences in the two models of behaviour. As noted earlier, however, role conflict is not inevitable as neither professionals nor bureaucracies exhibit all the distinguishing characteristics described above by Copur (1990). Two factors, likely to influence the extent of conflict experienced by professionals, are explored here.

The first is the extent to which a professional, once employed in an organization, maintains a high professional orientation or shifts their orientation towards the values and norms of the organization (Miller \& Wager, 1971). A person with a high professional orientation is one who primarily identifies with their professional group, is committed to developing and retaining the power and prestige of the profession, develops the abstract knowledge system, and looks to professional colleagues, both within and outside the organization, for support (Miller \& Wager, 1971; Abbott, 1988). It is this focus on the profession itself with its own code of ethics and models of conduct which is a distinctive characteristic of professionals (Abbott, 1988). While some professional groups, such as physicians, lawyers, academics, are often represented as those with a high professional orientation, there is increasing evidence that there are considerable variations in individual role orientations both within and between professional groupings (Aranya \& Ferris, 1984; Hall, 1967; Copur, 1990).

An individual's professional orientation is likely to vary depending on the extent to which a professional is prepared to give up some of the expectations of the role to which they were socialized in order to function as an employee (Lurie, 1981). As argued earlier, management deliberately implement socialization strategies to increase an individual's commitment to the goals and value system of the organization.
These strategies can act as a very powerful socialization agent and influence an individual's professional orientation once employed in an organization (Ouchi, 1979). If the work setting is the more powerful socialization agent, then role incompatibility is unlikely to emerge. Goode (1969) argued that compatibility between organizational and professional norms and values is likely to occur to a greater extent with "technical-scientific" professionals (e.g accounting, engineering) than with "person" professionals (law, medicine, university teaching). This suggests that some groups of professionals are more prepared than others to accommodate the need of bureaucracies by relinquishing some of their professional autonomy. Recent research, however, demonstrates that this is more likely to be due to historical and/or political and economic forces rather than to some unique characteristic of an occupational group. These forces influence the relative power of organizations to successfully bureaucratize professionals (Davies, 1983; Freidson, 1983; Barley \& Tolbert, 1991). ${ }^{5}$ Regardless of the factors which influence the organization's ability to socialize salaried employees, the apparent compatibility between professionals and bureaucracies is supportive of the notion that if individuals are able to give up some of the expectations associated with a high professional orientation, conflict can be minimized as they are able to accommodate the organization's concerns for efficiency and accountability (Aranya \& Ferris, 1984; Sitkin \& Sutcliffe, 1991; Derber \& Schwartz, 1991).

For some salaried professionals the primary and most powerful socialization agent will continue to be the profession. Professional groups have been able to remain the dominant socialization agent (or have gained dominances) within an organization ${ }^{6}$ because of the power

\footnotetext{
"Bacharach et al. (1991) note that these forces will shift over time and thus the characteristics of professionals and their relationship with the organization are not likely to remain static.

"The authority and power of professional groups within an organization can be at different stages of development. For example, physician authority in hospitals has been legitimized for many years and this group of professionals is currently concerned with maintaining that authority. Nursing, on the other hand, has traditionally not enjoyed such authority and is only relatively recently engaging in activities to develop professional autonomy (Fourcher \& Howard, 1981 ).
} 
and autonomy gained for members of the profession either by controlling the knowledge system or through industrial action (Abbott, 1988; Lurie, 1981; Friedson, 1975). A high professional orientation is, therefore, likely to be indicative of an individual's desire to achieve (or maintain) their autonomy in the work setting (Freidson, 1975). It follows that those individuals who demonstrate high levels of professional orientation will experience conflict in a bureaucratic organization as they will perceive management-related goals and obligations as contrary to their pursuit of autonomy.

A high professional orientation, however, does not necessarily lead to role conflict. The second factor which influences the degree of conflict experienced by salaried professionals is the extent to which their autonomy to operate independently is threatened by a requirement to adhere to administrative controls which are based on values and norms which are not in harmony with those of the professional (Freidson, 1970). Just as individual role orientations will differ so will the extent to which an organization (or subunit of an organization) attempts to impose tight administrative controls. As noted by Barley \& Tolbert (1991, p. 10) this is likely to be influenced by the organization's need for continuous access to specialized expertise as well as the extent to which professional groups, or individual professionals, come to dominate organization decision making once they have "established a foothold inside the organization's boundaries ..." It is also likely to be influenced by economic and political factors (Hopwood, 1984).

Administrative controls include both output and behaviour controls. Behaviour controls, such as the use of supervision, attempt to control behaviour by specifying behaviour which will lead to achievement of desired objectives and then observing if individuals behave in this manner. Financial controls such as budgeting are illustrative of output controls. Budgets operate as an output control by setting targets and measuring the extent to which the individual achieves these targets. A high professional orientation, with its emphasis on professional values and norms, is likely to be incompatible with a control environment dominated by administrative forms of control as these threaten professional autonomy. An environment which allows individuals with a high professional orientation to operative unencumbered by formal administrative controls is likely to reduce the potential for conflict. Thus, it is expected that imposing administrative controls which attempt to either control individual behaviour by specifying desired actions or achieve desired behaviour by specifying targets and measuring performance, is likely to have adverse organizational consequences where individuals have a high professional orientation. The confluence of a high professional orientation and a bureaucratic control environment will cause the emergence of role conflict. In contrast, if an individual with a high professional orientation is working in an environment where he/she is expected to rely on self-control or the social controls imposed by pecrs, we expect role conflict will be minimized.

\section{Hypothesis I}

In summary, we expect the interation between an individual's professional orientation and their control environment to have a significant impact on role conflict. We hypothesize that role conflict will be reduced where there is a match between professional orientation and the organization's control environment. Role conflict is used in the analytical model as the dependent variable. The hypothesis to be tested is stated as follows (in null form):

$\mathrm{H}_{1}$ There will be no significant interaction between professional orientation and the type of control environment affecting role conflict.

\section{Role conflict and organizational effectiveness-Hypothesis II}

Since Otley's (1980) review of the management accounting literature there has been an increasing demand for the inclusion of an effectiveness criterion variable in models of the type assessed in this study. While a match between the control environment and the 
individual's professional orientation is argued to impact on role conflict, the important question is whether this conflict has any adverse organizational effects. As noted earlier, management is often reluctant to accord professionals autonomy as there is a potential threat to the achievement of organizational objectives. Hospitals, in particular, have often been viewed by economists and sociologists as "simply inert turf upon which numerous individuals seek to maximize their own separate advantage" (Young \& Saltman, 1985 , p. 22). It is, therefore, important to establish the link between role conflict and organizational outcomes.

There is considerable support in the psychology literature that role conflict has adverse organizational consequences. Kahn et al. (1964) and others have reported numerous dysfunctional consequences of role conflict such as increases in job-related tension and turnover as well as decreases in job satisfaction, organizational commitment and overall performance (see Jackson \& Schuler, 1985, for a review of this literature).

To provide some evidence as to the likely impact of role conflict on organizational outcomes, two variables, used in prior literature namely, job satisfaction and subunit performance - are examined (Hirst, 1983; Brownell \& Dunk, 1991; Chenhall \& Brownell, 1988; Abernethy \& Stoelwinder, 1991). It is expected that increases in role conflict will have a negative impact on both job satisfaction and subunit performance. The following hypothesis (stated in null form) is tested:

$\mathrm{H}_{2}$ There is no significant relationship between role conflict and either job satisfaction or subunit performance.

\section{METHOD}

\section{Sample}

A questionnaire was administered to 100 physician and nurse subunit managers in a large hospital in Australia. This setting was particularly well suited to studying the way in which accounting is implicated in the relationship between professionals and organizations, as it has been very proactive in the development and implementation of sophisticated accounting control systems (Stoelwinder \& Abernethy, 1989). It is a teaching and research hospital with university medical and nursing school affiliations. Data collection was limited to nurse and physician managers to control for variables related to task and function. Both these groups are involved in teaching, research and patient care. ${ }^{7}$ All of the respondents were in middle management positions and performed both managerial and core operating tasks and it is in this situation where role conflict is most likely to emerge, as professionals in these positions are unable to avoid confronting the formal administrative control system (Sorensen \& Sorensen, 1974). Thus, variation on this construct was expected. A total of 91 usable questionnaires were returned yielding a response rate of 91 per cent.

The following variables were measured: professional orientation, control environment, role conflict, subunit performance and job satisfaction. Prior to the administration of the questionnaire, the measurement instruments used for each of these variables were tested on a "holdout" sample of nurse and physician managers. Any ambiguity in the wording of the items was removed in the final instrument. Each of the variables is discussed in turn.

\footnotetext{
${ }^{7}$ While physicians have typically been seen to have a monopoly on the research function in hospitals, the change to baccalaureate training for nurses has increased the research component of nurse education. Hospitals are also actively encouraging the involvement of nursing in research. For example, in the research site while the data were collected there was a nursing research officer to co-ordinate nursing research.
} 


\section{The independent variables}

Professional orientation. Few studies have attempted to measure professional orientation. A number of measures were considered. ${ }^{8}$ The instrument selected to measure professional orientation was one developed by Miller \& Wagner (1971) and Davis (1961). The instrument is not meant to capture professional behaviour, as such, but rather act as a proxy for the values which are perceived to be associated with a professional orientation (as opposed to a managerial or bureaucratic orientation), as defined in this study. This measure, therefore, focuses on the pursuit of academic knowledge which is argued to be the means by which a professional gains and maintains autonomy (Abbott, 1988). The instrument included the following five items:

(1) It is important to me that I be able to publish the results of my work in professional journals.

(2) It is important to me that I be able to pursue and carry out my own research ideas.

(3) Being able to do the kind of research that will contribute to the standing of my profession is very important to me.

(4) In the long run I would rather be respected (a) among specialists in my field outside the hospital or (b) in the hospital where I work.
(5) In the near future, I would most like (a) to publish a paper in the leading journal in my profession even though the topic may be of minor interest to the hospital, or (b) to make a major contribution to one of the hospital's projects.

With the exception of the last two items, the items were in a seven-point, fully anchored Likert-scale form. For the last two items respondents were required to choose either (a) or (b). To ensure that these items were weighted consistently with the first three items, they were coded using the inter-quartile points of the seven-point scale. The scores on the five items were then summed for use in the analysis. An alpha coefficient of 0.79 provides support for the internal reliability of the measure. ${ }^{9}$

Other data collected in this study provide some support for the construct validity of this measure. Recall that a professional orientation reflects the characteristics that may be perceived to be important to developing and maintaining the prestige of the profession, as opposed to the norms and values which are important to the functioning of bureaucratic organizations. Abernethy \& Stoelwinder (1991) measured bureaucratic values and norms using a construct based on Perrow's (1968) notion of system goals. The Abernethy and Stoelwinder (1991) system goal measure was included in this study as an indirect measure of the construct

\footnotetext{
${ }^{8}$ Length and type of education was considered, but a number of researchers (Miller \& Wagner, 1971; Kornhauser, 1962) argue that this represents the degree of socialization received by an individual prior to becoming an organization employee and thus does not necessary represent the role orientation of the individual. The three-item measure of professional activity used by Hage \& Aiken (1967) to represent organizational complexity was also considered. One of the items overlaps with the measure used in this study (publishing in professional journals), the second item measures membership in the organization and the third, attendance at professional meetings. These last two items were considered unlikely to represent a professional orientation as all physician managers are required to be registered with their professional association and nearly all nurses belong to their professional association as it is their industrial union. There is also no reason to believe that attendance at meetings is an activity which represents an individual's role orientation.

${ }^{9}$ While the use of an alpha coefficient for assessment of reliability of this instrument may be questionable owing to the presence of two binary variables, additional support for the reliability of this instrument was obtained. First, the correlations between the sum of the first three items and each of the binary variables were significant at less than 0.001 . Second, the sample was split based on the $0 / 1$ response for each of the binary variables and the means compared for each group. In both cases, the means were significantly different at less than the 0.001 level and in the direction predicted.
} 
validity of the professional orientation measure. As expected, the correlation between an individual's system goal orientation and professional orientation was negative and significant $(-0.18$, $p=0.05$ ). Further suppport for the validity of the professional orientation construct was provided by examining the relationship between an individual's professional orientation and their attendance at management training courses developed and conducted within the hospital. It is not unreasonable to expect that those individuals with a high professional orientation are likely to reject training programmes developed and conducted by those outside the profession. The point bi-serial correlation (Baggaley, 1964) between attendance at the hospital's management training course and professional orientation was negative and significant $(-0.33, p=0.001)$. While the support for the measure is indirect, it does confirm our expectations concerning characteristics of those with a high professional orientation, and thus adds some confidence to the validity of the construct.

Control environment. Three questions were asked which attempted to capture the respondent's perception of their control environment. For simplicity an individual's environment has been classified as either an administrative control environment or a professional control environment. An administrative control environment is one dominated by the use of output and behaviour controls and measured following Ouchi (1977) and Govindarajan \& Fisher (1990). A professional control environment is one which emphasizes social and self-control processes. Respondents were asked to select, by ticking the appropriate box, which of the following statements best reflected their superior's approach to them in managing their subunit

(a) Rather than focusing on the attainment of desired targets, my superior monitors my decisions and actions on an on-going basis.

(b) My superior focuses on the attainment of set targets for my unit and allows me consider- able discretion in deciding the best way of achieving these targets.

(c) Rather than specifying desired targets or monitoring my decisions and actions, my superior relies upon my professionalism to do the right thing by the hospital.

The first two statements represent behaviour and output controls, respectively. The third statement represents professional control. The variable was treated as a categorical variable in the analysis.

\section{Dependent variables}

Kole conflict. Kole conflict was measured using the instrument developed by Rizzo $e t$ al . (1970). The instrument has been tested widely in prior research and found to have high levels of validity and reliability (Schuler et al., 1977). An alpha coefficient (Cronbach, 1951) of 0.84 was derived in this study.

Subunit performance. Following other researchers, performance was measured using a single global rating (Merchant, 1981; Chenhall \& Brownell, 1988). Respondents were asked to rate their subunit performance from "well below average" to "well above average" on a fully anchored seven-point Likert-type scale. Although concern has been expressed regarding the use of self-reported measures of performance, there is no clear evidence that objective measures are either more reliable or valid in crosssectional studies (Brownell \& Dunk, 1991).

The concern over self-ratings of performance may be heightened in this study as the research question centres on the problems which occur when professionals pursue goals which are inconsistent with those of the organization and thus the respondents may have rated their subunit performance high in such circumstances whereas others would not. ${ }^{10}$ There is, however, some evidence that such concern is not warranted. Abernethy \& Stoelwinder (1991), using a similar research setting, took precautionary steps to avoid this problem. They asked

\footnotetext{
${ }^{10}$ We wish to thank the reviewer who identified potential difficulties in using a self-rating performance measure in this particular study.
} 
respondents to rate the importance superiors placed on a number of subunit performance criteria. Respondents were then asked to rate how superiors would have rated the subunit on each dimension. Abernethy \& Stoclwinder (1991) also asked each subunit manager to rate the subunit performance using the measure employed in this study. If there were divergences between the criteria considered important by the superior and subordinate, one would not expect a significant correlation between the two measures. However, the correlation between the two measures was positive and significant $(0.47, p<0.001)$. While this study only included an overall global measure, the high correlation between the alternative measures used by Abernethy \& Stoelwinder (1991) suggests that variability in superior's and subordinate's expectations of subunit performance might not be a major concern in this study.

Attempts were also made to use more objective measures of subunit performance by collection of superior ratings. However, both the director of medical services and director of nursing found it impossible to distinguish between the performance of 51 and 40 subunits, respectively. The medical director agreed to rate the best performers and worst performers. Fifteen of the physician-managed subunits were rated - nine were rated as top performers and six as poor performers. The respondents' selfratings were split at the mean and compared with the medical director's ratings. Some convergence was evident. Of the eleven managers who rated their subunit performance high, seven of these managers were also rated as top performers by the medical director.

Job satisfaction. This measure was based on the two-item scale developed by Dewar \& Werbel (1979). The reliability of the instrument has been tested and compares favourably with that of other instruments measuring job satisfaction (Dewar \& Werbel, 1979). Respondents were asked to indicate their agreement on the following two items: (a) all in all I am satisfied with my job; (b) in general I like working here. The scale was fully anchored with "one" representing strongly disagree and "seven" representing strongly agree. The two items were correlated at $0.77(p=0.000)$ and summed for use in the analysis.

\section{RESULTS}

The descriptive statistics and correlation matrix for all variables are presented in Table 1.

\section{Hypotbesis I}

To assess whether the match between professional orientation and the control environment affects role conflict, the following model was used: ${ }^{11}$

$$
\begin{aligned}
Y= & a_{0}+b_{1} X_{1}+b_{2} X_{21}+b_{3} X_{22}+ \\
& b_{4} X_{1} X_{21}+b_{5} X_{1} X_{22},
\end{aligned}
$$

where $Y$ is role conflict, $X_{1}$ is professional orientation, $X_{21}$ is the type of control ( $1=$ output control, $0=$ either behaviour or professional control), and $X_{22}$ is the type of control ( $1=$ bchaviour control, $0=$ either output or professional control).

The hypothesis was tested by examining the sign and significance of the coefficient of the two interaction terms $b_{4}$ and $b_{5}$ in equation ( 1 ). These coefficients capture the two-way interaction between $X_{1}$ and $X_{21}$ and $X_{22}$, respectively. Except for the $b_{4}$ and $b_{5}$ coefficients, the beta coefficients in equation (1) are not interpretable since they can be altered by shifting the origin points of $X_{1}$ and $X_{21}$ and $X_{22}$ (see Southwood, 1978; Allison, 1977; Govindarajan \& Fisher, 1990; Brownell \& Dunk, 1991).

To assist in the interpretation of the results and to assess if the null hypothesis is rejected in a fashion consistent with expectations - i.e. that a professional form of control will have a

\footnotetext{
"We would like to thank Professor Peter Brownell both for his suggestion that the model be specified so that differences between each form of control could be tested, and for his assistance in the specification of the model.
} 
TABLE 1. Pearson correlation matrix (significance levels)* and descriptive statistics

\begin{tabular}{|c|c|c|c|c|c|c|c|c|c|}
\hline Variable & 1 & 2 & 3 & 4 & $\begin{array}{c}\text { Theoretical } \\
\text { range }\end{array}$ & Min. & Max. & Mean & S.D. \\
\hline 1. Professional orientation & & & & & $7-31$ & 7 & 31 & 18.79 & 5.85 \\
\hline 2. Type of control & $\mathbf{N} / \mathbf{A}$ & & & & $1 / 2 / 3$ & $\mathbf{N} / \mathbf{A}$ & $\mathbf{N} / \mathbf{A}$ & N/A & $\mathbf{N} / \mathbf{A}$ \\
\hline 3. Role conflict & $\begin{array}{c}0.14 \\
(0.09)\end{array}$ & $\mathbf{N} / \mathbf{A}$ & & & $8-56$ & 8 & 55 & 28.41 & 11.1 \\
\hline 4. Performance & $\begin{array}{l}0.11 \\
\text { (ns) }\end{array}$ & $\mathbf{N} / \mathbf{A}$ & $\begin{array}{c}-0.44 \\
(0.000)\end{array}$ & & $1-7$ & 1 & 7 & 5.69 & 1.21 \\
\hline 5. Job satisfaction & $\begin{array}{l}-0.21 \\
(0.02)\end{array}$ & $\mathbf{N} / \mathbf{A}$ & $\begin{array}{c}-0.51 \\
(0.000)\end{array}$ & $\begin{array}{c}0.22 \\
(0.02)\end{array}$ & $2-14$ & 2 & 14 & 10.64 & 3.12 \\
\hline
\end{tabular}

$n=91$

- Pearson correlations (one-tailed test) were computed for all variables except the control variable as this is a categorical variable with three values. The significance levels for the correlations are in parentheses.

more positive effect on reducing role conflict when individuals have a high professional orientation than when either output or behaviour controls are used - equation (1) can be decomposed, and three functions, one for each control type, estimated, as follows: ${ }^{12}$

For output controls (where behaviour/professional controls are coded 0 ), equation (1) becomes:

$$
Y=\left(a+b_{2}\right)+\left(b_{1}+b_{4}\right) X_{1} .
$$

For behaviour controls (where output professional controls are coded 0 ), equation (1) becomes:

$$
Y=\left(a+b_{3}\right)+\left(b_{1}+b_{5}\right) X_{1} .
$$

For professional control (where both behaviour and output controls are coded 0 ), equation (1) becomes:

$$
Y=a+b_{1} X_{1} .
$$

To support the hypothesis we expected role conflict will be a significantly more positive function of professional orientation in both the output and behaviour control environment than in the professional control environment. Figure 1 illustrates our expectations. To test the hypothesis we need, therefore, to assess if the slope coefficients of $X_{1}$ differ significantly in the three control environments. To establish if the coefficients are significantly different in the three control environments (refer to equations (2-4)), it is necessary to look only at the $t$ statistics provided for $b_{4}$ and $b_{5}$ in equation (1). Inserting the coefficient estimates obtained from equation ( 1 ) (Table 2 ) into equations (24) provides the following coefficients for the $X_{1}$ variable:

For output control (equation (2)):

$$
Y=(27.73-18.36)+(-0.04+0.88) X_{1} .
$$

For behaviour control (equation (3)):

$$
Y=(27.73-5.96)+(-0.04+0.03) X_{1} .
$$

For professional control (equation (4)):

$$
Y=27.73-0.04 X_{1} \text {. }
$$

The significance of the differences between the slope coefficients for $X_{1}$ are given by the $t$ statistics for $b_{4}$ and $b_{5}$ in Table 2 . As indicated in the table, the $b_{4}$ coefficient is significant $(p=0.08)$ using a two-tailed test. This indicates that as professional orientation increases, the use of output controls is associated with significantly larger increases in role conflict compared with when professional control is in use. As the direction of the relationship was predicted it is not unreasonable to use a one-

\footnotetext{
12 This follows a similar decomposition employed by Brownell (1981) and Brownell \& Merchant (1990). In this paper, however, the three types of controls require the use of two dummy variables and the decomposition of results in three separate functions, one for each control system type.
} 


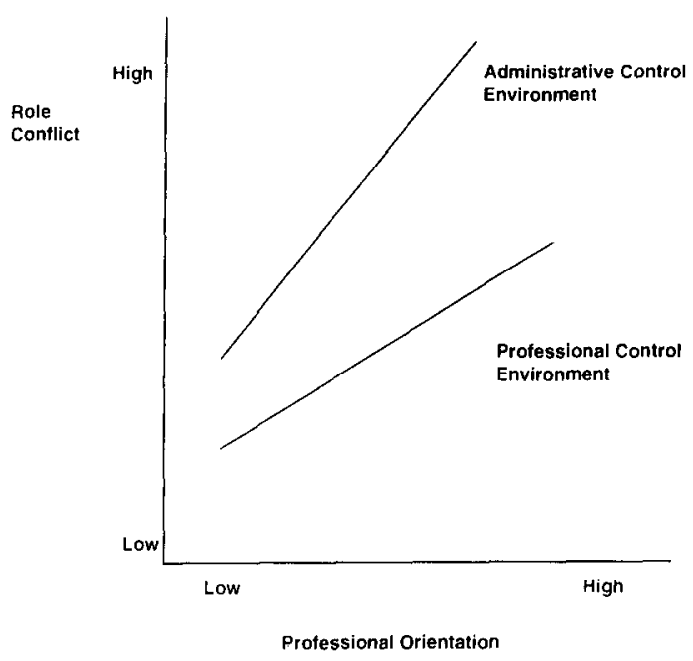

Fig. 1. Graphical representation of hypothesized relationship between type of control environment, professional orientation and role conflict.

tailed test, thus enabling a rejection of the null hypothesis of no interaction between the control environment and professional orientation affecting role conflict at a 95 per cent confidence level. As noted in Table 2 , the $b_{5}$ coefficient is not significant and thus does not enable rejection of the null hypothesis with respect to the use of behaviour controls.

\section{Hypothesis II}

The hypothesis to test the impact of role conflict on both job satisfaction and subunit performance is tested by examining the Pearson correlation coefficients presented in Table 1. The correlations support our expectations and indicate that increases in role conflict result in a significant decrease in both job satisfaction $(-0.51, p<0.001)$ and subunit performance $(-0.44, p<0.001)$.

\section{DISCUSSION AND CONCLUSION}

The organizational arrangements necessary to manage professionals in bureaucratic organizations continues to be of interest to sociologists (Barley \& Tolbert, 1991). Attention is currently being drawn to this issue in the management and accounting literatures owing to the increasing trend towards "professionalizing bureaucracies" and the pressure to impose even more sophisticated forms of administrative controls in these settings (Hopwood, 1984; Copur, 1990; Raelin, 1989; Preston et al., 1992). These concurrent trends create the milieu for conflict between the professional model of control and administrative control systems. There is concern in the literature that integrating professionals into bureaucratic organizations may not be effective when professionals, who wish to maintain their autonomy or are seeking to develop autonomy, confront formal administrative control systems which threaten this autonomy (Copur, 1990; Aranya \& Ferris, 1984). To date there has been no research which has

TABLE 2. Regression results relating to the relationship between professional orientation, control environment and their interaction on role conflict $(n=91)$

\begin{tabular}{lcccc}
\hline Coefficient & Value & S.E. & $t$ & Probability \\
\hline$a$ & 27.73 & 6.25 & 4.44 & 0.00 \\
$b_{1}$ & -0.04 & 0.26 & -0.15 & 0.88 \\
$b_{2}$ & -18.36 & 10.80 & -1.70 & 0.09 \\
$b_{3}$ & 5.96 & 12.59 & 0.47 & 0.64 \\
$b_{4}$ & 0.89 & 0.50 & 1.75 & 0.08 \\
$b_{5}$ & 0.03 & 0.51 & 0.05 & 0.96 \\
\hline $\boldsymbol{R}^{2}=0.11, F=2.20$, significance of $F=0.06$ & & & \\
$Y=a_{0}+b_{1} X_{1}+b_{2} X_{21}+b_{3} X_{22}+b_{4} X_{1} X_{21}+b_{5} X_{1} X_{22}$, & & & $(1)$
\end{tabular}

where $Y$ is role conflict, $X_{1}$ is professional orientation, $X_{21}$ is the type of control $(1=$ output control, $0=$ either behaviour or professional control), and $X_{22}$ is the type of control ( $1=$ behaviour control, $0=$ either output or professional control $)$. 
assessed how administrative controls, such as accounting, influence the relationship between professionals and bureaucracies. This paper attempted to do this by examining the effect of the interaction between professional orientation and the control environment on role conflict and the subsequent impact on organizational outcomes.

The results indicate that conflict between professional and bureaucratic norms and values is reduced when professionals with a high professional orientation do not operate in a control environment where output controls dominate and restrict them in their selfregulatory activities. These results are supportive of prior literature (Hall, 1967; Aranya \& Ferris, 1984; Organ \& Greene, 1981; Derber \& Schwartz, 1991). Further, the findings provide strong support that creating an environment which reduces role conflict has significant and positive effects on an individual's job satisfaction and overall subunit performance.

It would appear from the findings that the type of control environment which individuals with a high professional orientation find most offensive is one dominated by output forms of control, that is, an environment where superiors impose targets to be achieved and measure performance based on those targets. These findings are of particular relevance to management accountants as the primary form of output controls often involve the use of budgets and other financial targets. The results also have direct managerial and policy implications in hospitals and other human service industries where governments and third-party payers are creating pressure for the implementation of increasingly sophisticated management accounting systems, primarily to control professional behaviour. In settings where individuals have a high professional orientation, these attempts will be less than successful. Not only will these controls not operate effectively, they are likely to have adverse individual and organizational effects.

Since the results presented here indicate that it is the confluence of an individual's professional orientation and the control environment in which he/she works that creates adverse outcomes, management is faced with two options. First, it could attempt to reduce role conflict by implementing socialization and training policies to encourage professionals to forego some of the expectations of the professional role and accept the values and norms which underlie bureaucratic control systems. Caution, however, is required in the implementation of this strategy as it may be counter-productive. There is concern that professionals will become proletarianized if internal socialization strategies reduce their professional orientation to the extent that they yield control of the content and context of their work to the bureaucracy. In other words, the very "soul" of the professional may be threatened (Derber \& Schwartz, 1991, p. 89). They may "begin to resemble other workers in their job attitudes, satisfactions and discontents" (Copur, 1991, p. 115). One of the primary motives behind the push towards "professionalizing the bureaucracy" is to avoid and reduce such behaviour (Benveniste, 1987).

The second option is to encourage individuals to maintain their professional orientation and allow them to act "in accordance with their professional judgement" and "rely on the informal controls associated with professional membership" (Aranya \& Ferris, 1984, pp. 4-5). The conflict which often occurs when professionals are integrated into bureaucratic organizations is unlikely to occur under these conditions. The evidence indicates that it may be unnecessary to impose output forms of control as the use of professional control appears to have no adverse organizational consequences in this study. The results suggest that the creation of an appropriate organizational culture where professional values and goals are recognized may actually facilitate the achievement of the organization's goals. Indeed, professionals may perceive that the best way to achieve their own goals is through the achievement of organizational goals.

While the findings in this study shed some light on control systems in professionally dominated organizations, it is necessary to recognize that models, such as the one studied 
here, do not enable the complexities of managing such organizations to be fully captured. For example, we were somewhat surprised to find that a behaviour control environment (i.e. one where the superior monitored the behaviour of the subordinate) did not result in increasing role conflict to any greater extent than in a professional control environment. This result may reflect the fact that supervision is not perceived as an administrative control by this group of managers. The superiors of the respondents were, in every case, fellow professionals and, therefore, supervision may be perceived as originating from outside the organization and within the self-governing structure of the profession. If the authority for supervision of professional work comes from professional expertise, it is likely to be seen as an acceptable means of control (Blau, 1968; Freidson, 1975).

The solution to the "control" problem in professionally dominated organizations such as hospitals is equally complex. Market approaches to public sector management are being implemented in a variety of countries. Large public hospitals such as the one studied here will need to manage both means and ends if they are to be price competitive or to deliver on the cost and quality targets specified in purchaser contracts. Some form of acceptable output control will need to be implemented. As professionals are key players in achieving these targets, it is unlikely that it will be feasible to buffer them from administrative forms of control. The challenge for hospital management will be to design management control systems which balance the competing demands of dominant professionals and those purchasing hospital services.

Several limitations of the study should be noted. As with all cross-sectional survey studies, the results do not constitute proof of the relationships. Rather, the evidence presented can only be said to be consistent with the theoretical position developed in the paper. As the study was undertaken in only one organizational setting, further research is required to assess if these relationships hold in other similar organizations and in other settings where professional control is employed extensively. Several of the measures used in this study require further testing. While the variables of interest were measured using instruments previously employed by other researchers, there are few studies which have used the Miller \& Wager (1971) and Ouchi (1979) instruments. Further psychometric assessment of these instruments is required. Additional measures of performance, which could be externally verified, might also enhance the measurement of performance.

Notwithstanding these limitations, this study does provide some insight into the nature of control processes in complex organizations dominated by professionals and illustrates how the potentially conflicting control cultures associated with professionals and bureaucratic organizations can be effectively managed.

\section{BIBLIOGRAPHY}

Abbott, A., The System of Professions (Chicago: University of Chicago Press, 1988).

Abernethy, M.A. \& Stoelwinder, J. U., Budget Use, Task Uncertainty, System Goal Orientation and Subunit Performance: A Test of the "Fit" Hypothesis in Not-for-Profit Hospitals, Accounting, Organizations and Society (1991) pp. 105-120.

Allison, P. D., Testing for Interaction in Multiple Regression, American Journal of Sociology (1977) pp. 144-153.

Aranya, N. \& Ferris, K. R., A Reexamination of Accountants' Organizational-Professional Conflict, The Accounting Review (1984) pp. 1-15.

Bacharach, S. G., Bamberg, P. \& Conley, S. C., Negotiating the "Sea-Saw" of Managerial Strategy: A Resurrection of the Study of Professionals in Organizational Theory, Research in Sociology of Organizations ( 1991 ) pp. 217-240. 
Baggaley, A. R., Intermediate Correlation Methods (New York: Wiley, 1964).

Barley, S. R. \& Tolbert, P. S., At the Intersection of Organizations and Occupations, Research in Sociology of Organizations (1991) pp. 1-16.

Benveniste, G., Professionalizing the Organization: Reducing Bureaucracy to Enbance Effectiveness (San Francisco: Jossey-Bass, 1987).

Birnberg, J. G. \& Snodgrass, C., Culture and Control: A Field Study. Accounting, Organizations and Society (1988) pp. 447-464.

Blau, P. M., The Hierarchy of Authority in Organizations, American Journal of Sociology (1968) pp. 453-467.

Broadbent, J., Laughlin, R. \& Read, S., Recent Financial and Administrative Changes in the NHS: A Critical Theory Analysis, Critical Perspectives on Accounting (1991) pp. 1-29.

Brownell, P., Participation in Budgeting, Locus of Control and Organizational Effectiveness, The Accounting Review (1981) pp. 844-860.

Brownell, P. \& Dunk, S. A., Task University and its Interaction with Budgetary Participation and Budget Emphasis: Some Methodological Issues and Empirical Investigation, Accounting, Organizations and Society (1991) pp. 693-703.

Brownell, P. \& Merchant, K. A., Budget System Design: The Influence of Product and Process, Journal of Accounting Research (1990) pp. 388-397.

Chenhall, R. H. \& Brownell, P., The Effect of Participative Budgeting on Job Satisfaction and Performance: Role Ambiguity as an Intervening Variable, Accounting, Organizations and Society (1988) pp. $225-234$.

Chua, W. F. \& Degeling, P., Information Technology and Accounting in the Accomplishment of Public Policy - A Cautionary Tale, Accounting, Management and Information Tecbnology (1991) pp. $109-137$.

Chua, W. F. \& Degeling, P., Interrogating an Accounting-based Intervention on Three Axes: Instrumental, Moral and Aesthetic, Accounting, Organizations and Society (1993) pp. 291-318.

Copur, H., Academic Professionals: A Study of Conflict and Satisfaction in Professoriate, Human Relations (1990) pp. 113-127.

Cronbach, L. J., Coefficient Alpha and the Internal Structure of Tests, Psychometrika (1951) pp. 297-334.

Crozier, M., The Bureaucratic Pbenomenon (Chicago: University of Chicago Press, 1964).

Davies, C., Professionals in Bureaucracies: The Conflict Thesis Revisited, in Dingwall, R. and Lewis, P. (eds), The Sociology of Professions (London: The MacMillan Press, 1983).

Davis, J. A., Local and Cosmopolitans in American Graduate Schools, International Joumal of Comparative Sociology ( 1961 ) pp. 212-223.

Derber, C. \& Schwartz, W. A., New Mandarins or New Proletariat?: Professional Power at Work, Research in the Sociology of Organizations (1991) pp. 71-96.

Dewar, R. \& Werbel, J., Universalistic and Contingency Predictions of Employee Satisfaction and Conflict, Administrative Science Quarterly (1979) pp. 313-327.

Fourcher, L. A. \& Howard, M. J., Nursing and the "Managerial Demiurge", Social Science arud Medicine (1981) pp. 299-306.

Freidson, E., Professional Dominance: The Social Structure of Medical Care (Atherton: New York, 1970).

Freidson, E., Doctoring Together: A Study of Professional Social Control (University of Chicago Press: Chicago, 1975).

Freidson, E., The Theory of Professions: State of the Art, in Dingwall, R. and Lewis, P. (eds), The Sociology of Professions (London: The MacMillan Press, 1983).

Ginsberg, A., Measuring and Modelling Changes in Strategy: Theoretical Foundations and Empirical Directions, Strategic Management Journal (1988) pp. 559-575.

Goode, W. J., The Theoretical Limits of Professionalization, in Etzioni, A. (ed.), The Semi-Professions and their Organizations (The Free Press, 1969).

Govindarajan, V. \& Fisher, J., Strategy, Control Systems, and Resource Sharing: Effects on Business-units Performance, Academy of Management Journal (1990) pp. 259-285.

Hage, J. \& Aiken, M., Relationship of Centralization to Other Structural Properties, Administrative Science Quarterly (1967) pp. 72-92.

Hall, R. H., Some Organizational Considerations in the Professional-Organizational Relationship, Administrative Science Quarterly (1967) pp. 461-478.

Hellriegel, D. \& Slocum, J. W. Jr, Management (Reading: Addison-Wesley, 1986).

Hirst, M. K. Reliance on Accounting Performance Measures, Task Uncertainty and Dysfunctional Behaviour: Some Extensions, Journal of Accounting Research (1983) pp. 596-605. 
Hopwood, A., Accounting and the Pursuit of Efficiency, in Hopwood, A. \& Tomkins, C. (eds), Issues in Public Sector Accounting (Oxford: Phillip Allan, 1984).

Hopwood, A., Accounting and Human Bebaviour (Englewood Cliffs: Prentice Hall, 1976).

Jackson, S. E. \& Schuler, R. S., A Meta-analysis and Conceptual Critique of Research on Role Ambiguity and Role Conflict in World Settings, Organizational Bebavtor and Human Decision Processes (1985) pp. $16-78$.

Johnson, T. J., The Professions in the Class Structure, in Scase, R. (ed.), Industrial Society, Class, Cleavage and Control, pp. 93-110 (London: Allen \& Unwin, 1977).

Kahn, D., Wolfe, D, Quinn, R., Snoek, J. \& Rosenthal, R., Organizational Stress: Studies in Role Conflict and Ambiguity (New York: Wiley, 1964).

Kornhauser, W., Scientists in Industry (Berkeley: University of California Press, 1962).

Lurie, E. E., Nurse Practitioners: Issues in Socialization, Joumal of Healtb and Social Bebaviour (1981) pp. 31-48.

Merchant, K. A., The Design of Corporate Budgeting Systems: Influence on Managerial Behavior and Performance, The Accounting Review (1981) pp. 813-829.

Merchant, K. A., Control in Business Organizations (Cambridge: Ballinger, 1985).

Miller, G. A. \& Wager, L. W., Adult Socialization, Organizational Structure and Role Orientations, Administrative Science Quarterly (1971) pp. 151-163.

Mills, P. K., Self-Management: Its Control and Relationship to Other Organizational Properties, Academy of Management Review (1983) pp. 445-453.

Mintzberg, H., The Structuring of Organizations (Englewood Cliffs: Prentice Hall, 1979).

Montagna, P. D., Professionalization and Bureaucratization in Large Professional Organizations, American Journal of Sociology (1968) pp. 138-145.

Organ, D. W. \& Greene, C. N., The Effects of Formalization on Professional Involvement: A Compensatory Process Approach, Administrative Science Quarterly (1981) pp. 237-252.

Orlikowski, W. J., Integrated Information Environment or Matrix of Control? The Contradictory Implications of Information Technology, Accounting Management and Information Tecbnologies (1991) pp. $9-42$.

Otley, D. T., The Contingency Theory of Management Accounting: Achievement and Prognosis, Accounting, Organizations and Society (1980) pp. 413-428.

Ouchi, W. G., A Conceptual Foundation for the Design of Organizational Control Mechanisms, Management Science (1979) pp. 833-848.

Packwood, T., Keen, J. \& Buxton, M., Hospitals in Transition: The Resource Management Experiment (Buckingham, U.K.: Open University Press, 1991).

Perrow, C., Organization Goals, in Sills, D. L. (ed.), International Encyclopedia of the Social Sciences: $I I$ (New York: Macmillan and the Free Press, 1968).

Perrow, C., Complex Organizations: A Critical Essay (New York: Random House, 1986).

Pollitt, C., Harrison, S., Hunter, D. \& Narnoch, G., The Reluctant Managers: Clinicians and Budgets in the NHS, Financial Accountability and Management (1988) pp. 213-33.

Preston, A. M., Cooper, D. J. \& Coombs, R. W., Fabricating Budgets: A Study of the Production of Management Budgeting in the National Health Service, Accounting, Organizations and Society (1992) pp. 561-594.

Raelin, J. A., The Clasb of Culture - Managers and Professionals (Boston: Harvard Business School Press, 1989).

Rizzo, J. R., House, R. J. \& Lirtzman, S. I., Role Conflict and Ambiguity in Complex Organizations, Administrative Science Quarterly (1970) pp. 150-163.

Schuler, R. S., Aldag, R. J. \& Brief, A. P., Role Conflict and Ambiguity: A Scale Analysis, Organizational Bebavior and Human Performance (1977) pp. 111-128.

Scott, W. R., Professionals in Bureaucracies - Areas of Conflict, in Vollmer, H. M. \& Mills, D. L. (eds), Professionalization (Englewood Cliffs: Prentice Hall, 1966).

Shortell, S. M., Morrison, E. M. \& Friedman, B., Strategic Cboices for America's Hospitals: Managing Cbange in Turbulent Times (San Francisco: Jossey Bass, 1990).

Sitkin, S. B. \& Sutcliffe, K. M., Dispensing Legitmacy: The Influence of Professional, Organizational and Legal Controls of Pharmacist Behavior, Research in the Sociology of Organizations (1991) pp. 269-295.

Sorensen, J. E. \& Sorenson, T. C., The Conflict of Professionals in Bureaucratic Organizations, Administrative Science Quarterly (1974) pp. 98-106. 
Southwood, K. E., Substantive Theory and Statistical Interaction: Five Models, American Journal of Sociology (1978) pp. 1154-1203.

Stoelwinder, J. U. \& Abernethy, M. A., The Design and Implementation of a Management Information System for Australian Public Hospitals, Healtb Services Management Research (1989) pp. 176-190.

Tolbert, P. S. \& Stern, R. N., Organizations of Professionals: Governance Structures in Large Law Firms, Research in the Sociology of Organizations (1991) pp. 97-118.

Wolfe, D. M. \& Snoke, J. D., A Study of Tensions and Adjustment Under Role Conflict, Journal of Social Issues (1962) pp. 102-121.

Young, D. W. \& Saltman, R. B., The Hospital Power Equilibrium, Physician Bebavior and Cost Control (Baltimore: Johns Hopkins University Press, 1985).

Zucker, L. G., Markets for Bureaucratic Authority and Control: Information Quality in Professions and Services, Research in the Sociology of Organizations (1991) pp. 157-190. 